\title{
Educação Ambiental em contextos não escolares: definindo, problematizando e exemplificando
}

\author{
Maria Inês Gasparetto Higuchi ${ }^{1}$ \\ Michelle Zattoni ${ }^{2}$ \\ Fernando Protti Bueno ${ }^{3}$
}

Resumo: Falar em Educação Ambiental é pensar numa complexidade de temas, objetivos e contextos. No ano de 2011, por ocasião do VI Encontro de Pesquisa em Educação Ambiental (EPEA), ocorrido em Ribeirão Preto, SP, um grupo com representantes de boa parte do Brasil tomou para si a discussão da EA em diferentes contextos. Aqui apresentamos um recorte das reflexões ocorridas no Grupo de Discussão de Pesquisa, o qual inclui a problematização e alguns exemplos de atividades relativas ao processo de Educação Ambiental em contextos não escolares. O texto mostra que vivências com e na natureza podem contribuir afetiva e cognitivamente para que haja maior respeito e cuidado para com o ambiente.

Palavras-chave: Contextos não escolares. Educação ao ar livre. Natureza.

\section{Environmental Education in non-school contexts: defining, discussing and exemplifying}

\begin{abstract}
To speak of Environmental Education is to think of a complexity of themes, goals and contexts. In 2011, during the VI Research Meeting on Environmental Education (EPEA), held in Ribeirão Preto, São Paulo, Brazil, a group formed by researchers from most parts of Brazil discussed EE in different contexts. Here is an outline of the reflections occurred in the Research Discussion Group, with questions and examples of activities related to Environmental Education in nonschool contexts. This text shows that some experiences with and in contact with nature can provide the participants with emotional and cognitive means towards environmental awareness and care.
\end{abstract}

\footnotetext{
${ }^{1}$ Pesquisadora titular do Instituto Nacional de Pesquisas da Amazônia, coordenando o Laboratório de Psicologia e Educação Ambiental. higuchi.mig@gmail.com

${ }^{2}$ Bióloga, mestre em Agroecologia e Desenvolvimento Rural pelo Centro de Ciências Agrárias da Universidade Federal de São Carlos (UFSCar), São Carlos, Brasil, michellezattoni@gmail.com

3 Professor assistente no curso de Turismo da UNESP - Universidade Estadual Paulista - Campus de Rosana, sendo responsável pelas disciplinas de agências de viagens, ecoturismo, transportes e turismo náutico.Rosana, Brasil, fbueno@rosana.unesp.br
} 
Keywords: Non-school contexts. Outdoor education. Nature.

\section{Educación Ambiental en contextos no escolares: definiendo, problematizando y ejemplificando}

Resumen: Hablar en Educación Ambiental es pensar en una complejidad de temas, objetivos y contextos. En el año de 2011, por ocasión del VI Encuentro de Investigación en Educación Ambiental (EPEA), ocurrido en Ribeirão Preto, SP, un grupo con representantes de buena parte de Brasil tomó para sí la discusión de la EA en diferentes contextos. Aquí presentamos un recorte de las reflexiones ocurridas en el Grupo de Discusión de Investigación, que incluye la problematización y algunos ejemplos de actividades relativas al proceso de Educación Ambiental en contextos no escolares. El texto muestra que vivencias con y en la naturaleza pueden contribuir afectiva y cognitivamente para que haya mayor respeto y cuidado para con el ambiente.

Palabras clave: Contextos no escolares. Educación al aire libre. Naturaleza.

\section{Introdução}

A Educação Ambiental (EA) está cada vez mais presente no espaço da coletividade. No entanto, os significados e compreensões dados a ela são bastante distintos e não raro confusos. Se falar em Educação Ambiental já envolve a complexidade que lhe é peculiar, como estaria a compreensão dos espaços destinados aos acontecimentos entendidos como âmbito de sua atuação? Essa temática tem sido objeto de reflexão nos Grupos de Discussão de Pesquisa que ocorrem por ocasião do Encontro de Pesquisa em Educação Ambiental (EPEA). No ano de 2011, no evento ocorrido em Ribeirão Preto, SP, um grupo com representantes de boa parte do Brasil tomou para si a discussão da EA em diferentes contextos. Aqui apresentamos um recorte dessa reflexão, que inclui definições, problematização e alguns exemplos de atividades relativas aos contextos não escolares.

Inicialmente foi necessário compreender o próprio termo "contextos não escolares". Vemos que no Dicionário Aurélio da Língua Portuguesa a palavra contexto significa desde 'encadeamento de ideias' até 'conjunto' - totalidade, assunto, argumento e composição. Temos, portanto, um significado de abrangência de acontecimentos que envolve, sobretudo, adição de agentes e elementos. Há, por certo, uma dinamicidade, um movimento intrínseco nesse acontecimento. Para efeito de nossa discussão, consideramos contexto como um espaço de acontecimento social que não se limita por barreiras físicas, mas por territorialidades fluidas e intencionalidades próprias que transcendem aspectos de lugar. Existe, no entanto, uma dimensão temporal estabelecida como marcação de acontecimentos. 
Processos de educação têm sido mais frequentemente caracterizados como educação formal, educação não formal ou educação informal. Todas trazem implícito um lugar diferenciado da sua ocorrência. Alguns autores se preocuparam em discutir essas denominações, que surgiram da compreensão das limitações da escola como espaço único de educação num mundo com complexidade e amplitude sociológicas gigantes (FÁVERO, 2007; PALHARES, 2008). Todavia, o "não escolar" é uma referência a uma proposta que emerge de planejamento e execução que não requerem relações de controle curricular. É também uma expansão da reflexão para além dos limites meramente escolares, isto é, reflexão sobre o papel de outros espaços como instâncias de reprodução ou mudança social (PALHARES, 2008).

Segundo Fávero (2007), a “comparação com a 'vida escolar' é inevitável, não porque a escola é formal - efetivamente o é, nos seus elementos estruturais -, mas porque deixou de abrigar, sobretudo quando foi estendida para as camadas populares, a riqueza de seus espaços e tempos não-formais". Dessa forma, o caráter da não formalidade permite maior liberdade na seleção e organização de conteúdos e metodologias, o que amplia as possibilidades de interdisciplinaridade e contextualização, as quais são limitadas nos contextos escolares pela falta de flexibilidade e fragmentação da realidade na escolarização vigente (GUIMARÃES; VASCONCELOS, 2006).

A Educação Ambiental num contexto não escolar se constitui num espaço de diálogos abertos às proposições inovadoras de integração, articulação e acolhimento de audiências e experiências socioambientais amplas. Assim, a escola, como lugar formal, pode conter tanto a educação "escolar-formal" quanto a "não escolar-não formal e informal". O termo contexto pode auxiliar nesse entendimento livrando-se de amarras físicas para transcender os espaços criados dentro de um lugar distinto.

Uma vez estabelecido esse entendimento, seguimos na necessidade de nos perguntarmos sobre o público ao qual se dirige uma educação designada num contexto não escolar. Novamente, não se trata de dividir papéis e funções sociais dos atores caracterizados como participantes de determinado processo educativo, mas de entender como eles se situam nesse universo de diálogos em dado espaço e momento. Como parte da reflexão grupal, é imperioso que esse público tenha como distinta sua condição social pelo fato de serem cidadãos que vivem historicamente em situações de sofrimento, de invisibilidade social e de exclusão (na cidade ou no campo). Dessa forma, o processo educativo tem como premissa básica a reflexão e o empoderamento desses atores para que adquiram competências nas relações sociais que os levam a se comportar de formas diversas no ambiente.

A função desempenhada como formador, gestor ou usuário de frentes múltiplas, como materiais educativos, recursos midiáticos e redes sociais, caracteriza possibilidades de engajamento do indivíduo em processos educativos 
em contextos não escolares. Ademais, a condição de ser consumidor ou agente de uso da terra e dos recursos ambientais é critério genuíno que o garante como público-alvo para essas atividades. Essas são apenas algumas das características com que o ator social envolvido seria identificado como público de um processo educativo num contexto não escolar.

O educador envolvido nesses processos acredita que a Educação Ambiental é ampla e abrangente e, sobretudo, tem uma ideologia voltada para a transformação social a partir do desejo de promoção da justiça social. Além disso, tem em mente aspectos de relevância de um acontecimento coletivo para buscar a proposição de políticas públicas ou de processos educativos ou de gestão para mudar práticas que inviabilizem vivências justas e sustentáveis. Considerando esses aspectos constituintes de uma Educação Ambiental em contextos não escolares, que tipo de abordagem seria mais adequada?

\section{Sobre Educação Ambiental}

Vários autores já se dedicaram a abordar as diversas maneiras de conceber e praticar a ação educativa (LAYRARGUES, 2010; SAUVÉ, 2005; SORRENTINO, 1995). Mesmo com denominações diferenciadas, essas concepções, segundo Sauvé (1997), têm similaridades, tais como tratar da educação sobre o meio ambiente, no meio ambiente, para o meio ambiente e $a$ partir do meio ambiente. Nessas vertentes há marcos teórico-metodológicos que se configuram como conservacionistas ou da critica social.

A EA conservacionista, segundo Sorrentino (1995), se atém ao pragmatismo em torno das preocupações ambientais, de modo especial na conservação dos recursos naturais (SAUVÉ, 2005). Já a EA crítica, também chamada de EA transformadora, emancipatória ou libertária, incorpora a discussão sobre degradação ambiental e humana e tem sua origem nos ideais democráticos e emancipatórios do pensamento crítico aplicado à educação (CARVALHO, 2008; CATALÃO, 2006; GUIMARÃES, 2004; LOUREIRO, 2004). No campo da EA está inserida a especificidade de compreender as relações sociedade-natureza e intervir nos problemas e conflitos ambientais (CARVALHO, 2001). Essa corrente está orientada para um processo permanente, cotidiano e coletivo pelo qual agimos e refletimos para transformar a realidade de vida, uma vez que é uma possibilidade que congrega o amplo diálogo para um novo pensar e um novo agir (HIGUCHI; AZEVEDO, 2004).

Nesse objetivo de estimular uma nova relação entre a sociedade e o seu ambiente, novas condutas são esperadas. Entre tantas condutas há uma preocupação muito forte em relação ao ambiente natural. Mesmo com perguntas próprias de quão natural seria um ambiente (FLORIANI, 2000), ambiente natural será referido como natureza, ou seja, um lugar de predominância da flora e da fauna em sua forma nativa (HIGUCHI; AZEVEDO; FORSBERG, 2012). 
Sendo a natureza o aspecto central da preocupação ambiental, várias abordagens educativas incluem processos com múltiplas dimensões de alcance, aproximando o que nunca poderia estar separado: natureza/sociedade, indivíduo/coletividade, físico/social, escolar/não escolar, entre outras tantas facetas.

\section{Educação Ambiental em vivências com e na natureza}

A relação dos seres humanos com a natureza é historicamente depredatória, mesmo quando esses consideram todos os benefícios e importância dela (HIGUCHI; AZEVEDO; FORSBERG, 2012). Tal modo de pensar e agir tem contribuído para a emergência de problemas de magnitude planetária, como, por exemplo, as mudanças climáticas. Um novo ethos parece evidentemente necessário e, portanto, esse ambiente natural se constitui em um espaço educativo não escolar que propicia aprendizagens significativas de transformação, se devidamente encaminhadas. Vivências educativas com e na natureza, conhecidas como educação ao ar livre, tiveram sua origem entre naturalistas que incentivavam as caminhadas ecológicas, as trilhas de interpretação da natureza, o turismo ecológico e o autoconhecimento na relação com a natureza como momento de reflexão e transformação de condutas socioambientais (BRASIL, 1999; LEONARDI, 1999; SORRENTINO, 1995 apud LEONARDI, 1999). Apesar de poder se referir a outras dimensões do ambiente, o termo "ao ar livre" é ainda atrelado ao contato presencial com a natureza ou a floresta.

Para a realização da Educação Ambiental ao ar livre é essencial a existência de espaços propícios a vivências diretas com e na natureza, uma vez que essa imersão é fator mediador da transformação. $O$ estímulo a esse procedimento educativo está presente em várias propostas, inclusive no Programa Nacional de Educação Ambiental (PNEA) e nos planos específicos de gestão de Unidades de Conservação (UC) de uso indireto (BRASIL, 1999, 2000). Essas vivências de imersão na natureza despertam emoções e motivações capazes de iniciar mudanças na relação pessoa-ambiente, focando a proteção e o cuidado ambiental (SOUZA JÚNIOR; ITO, 2005; TUAN, 1980).

O lugar não é, contudo, suficiente para que esse procedimento seja transformador de comportamento, uma vez que é a prática pedagógica e suas técnicas que são vitais para vivências eminentemente educativas. Nesse sentido, Bueno (2006) resumiu três propostas metodológicas para a Educação Ambiental ao ar livre: a) aprendizado sequencial (AS); interpretação ambiental (IA); c) educação experimental (EE).

O aprendizado sequencial, criado pelo naturalista Joseph Cornell, é considerado original para auxiliar e tratar de maneira profunda a interação que se pode ter com a natureza. O AS tem como estratégia de ensino a escolha de atividades lúdicas, como dinâmicas e jogos, a serem desenvolvidas sempre em áreas verdes 
ou fragmentos florestais em seu estado conservado (MENDONÇA, 2000, 2006). Segundo Cornell (1997), tais aspectos são importantes porque as vivências ali desenvolvidas permitem que a pessoa penetre de maneira completa no espírito do mundo natural, o que auxilia a descoberta interna do profundo sentimento de pertinência e compreensão relacionado a este mundo. $\mathrm{O}$ autor afirma ainda que o desenvolvimento de sentimentos de afetividade e de preocupação para consigo, para com os outros, para com a natureza e para com os demais seres que nos cercam é a base para a construção de um processo de transformação, pois caso contrário nunca seremos tocados de maneira profunda.

Ao longo de suas experiências com a natureza, Cornell percebeu que havia uma sequência pedagógica a ser trabalhada para que as atividades fossem mais produtivas na construção de uma consciência que emerge de vivências específicas com o corpo e no corpo (CORNELL, 1997; SHARING NATURE FOUNDATION, 2008). Esse AS é viabilizado por meio de dinâmicas e jogos organizados e direcionados numa sequência de quatro estágios: a) despertar o entusiasmo, b) concentrar a atenção, c) dirigir a experiência e d) compartilhar a inspiração. Essa sequência é desenvolvida de forma sutil, gradativa e divertida, com a intenção de criar um fluxo de energia que vai de um estado de maior agitação para um estado de maior envolvimento e concentração. Esses estágios fluem de um para o outro de maneira suave e natural, configurando assim um processo educativo em que o indivíduo alcança as estruturas mentais proporcionadas pelas experiências diretas e profundas com a natureza (CORNELL, 1997; INSTITUTO ROMÃ, 2008).

A interpretação ambiental (IA), por outro lado, constitui tanto um ato quanto um enfoque da comunicação, já que se vale de informações e emoções em relação à temática em foco (HAM, 1992; MURTA; GOODEY, 2002). A interpretação, segundo Murta e Goodey (2002, p. 13), é capaz de revelar significados, provocar emoções e estimular a curiosidade. Esse estado de vivência emotiva e lúdica inspira novas atitudes em relação ao ambiente e pode inclusive transcender para outros aspectos do cotidiano (HAM, 1992). As qualidades presentes na abordagem da IA estão no seu modo ameno e tranquilo de transmitir as informações. A transmissão deve ocorrer de forma peripatética, sendo o ponto central o elemento à frente nessa caminhada sem pressa. Além disso, essa interpretação deve ser pertinente, interessante e envolvente. Em todos esses casos deve haver cuidado na organização e planejamento dos recursos didáticos que irão mediar a aprendizagem. Por isso, a IA requer um foco temático, um assunto que seja central em cada momento educativo. O tema escolhido facilita o ajuste da concentração e do investimento cognitivo e afetivo. A IA, para Murta e Goodey (2002), visa valorar a experiência, ressaltando as representações e as informações relativas às características históricas, culturais e naturais de determinada localidade. 
A educaşão experiencial (EE) surgiu como um dos primeiros programas de educação ao ar livre nos Estados Unidos. Em 1941, o educador alemão Kurt Hahn fundou a escola Outward Bound com o objetivo de treinar jovens marinheiros que iriam à guerra para que percebessem e acreditassem em seu potencial e sua força, pois estavam morrendo em maior quantidade do que os marinheiros mais velhos (BARROS, 2000). Ao longo dos anos se consolidou como uma prática educacional que utiliza como recurso de aprendizagem os próprios desafios encontrados em ambientes naturais.

As situações de aventura vivenciadas nesses espaços, segundo Barros (2000), levam o ser humano a se deparar com suas limitações e seus conflitos com mais eficácia do que a simples discussão de possibilidades e dificuldades. As situações proporcionadas pela EE levam o indivíduo a confrontar aspectos de si mesmo, até o momento desconhecidos. As experiências vividas de modo individual, com o grupo e com o ambiente, acrescidas com a posterior reflexão, promovem empatia e maior interesse por problemas relacionados aos recursos naturais. Barros (2000), apoiada em outros autores, lembra que a aplicação dessa metodologia depende da existência de diferentes elementos e dos estágios de estrutura, desafio, experiência e reflexão (LUCKNER; NADLER, 1992 apud BARROS, 2000; OUTWARD BOUND BRASIL, 2005). Esse processo, segundo Barros (2000), pode ter a duração de poucas horas ou até mesmo meses.

Apesar de serem caracterizadas de forma distinta, essas três propostas metodológicas podem se complementar entre si e trazer novas formações de aprendizagem, da mesma forma que tais contextos não escolares podem ser efetivamente ocupados por protagonistas advindos da escola. Para exemplificar essas possibilidades, apresentamos experiências desenvolvidas por grupos de alunos/as e grupos de professores/as em São Paulo e Manaus, respectivamente.

\section{Experiências em contextos não escolares}

A partir de uma proposta de inserção da questão ambiental da Escola Municipal de Educação Básica Camine Botta, de São Carlos (SP), estudantes do oitavo ano e professoras/es foram mobilizados para uma sensibilização em relação à proteção de ambientes naturais. Visitas monitoradas a um sítio foram realizadas com grupos de alunos/as e professores/as de modo a vivenciar aspectos distintos da educação ao ar livre. As vivências, informações e reflexões tinham como meta a proposição de um programa complementar no contexto escolar, isto é, esses participantes estariam replicando tais vivências aos alunas/os das séries precedentes.

A proposta envolveu inicialmente encontros com as/os professoras/es para a socialização dos objetivos e acordos mínimos. Uma vez acertados esses detalhes, os/as alunos/as e professores/as se deslocaram a um sítio nos 
arredores da cidade, fizeram trilhas interpretativas e vivenciaram situações específicas desse ambiente com uma mata reflorestada (APP) e um rio (Ribeirão Feijão) que passa ao fundo da propriedade e auxilia no abastecimento de água da cidade. Além disso, nesse sítio todo o esgoto é tratado com tecnologias desenvolvidas pela Embrapa Instrumentação. A horta, mantida com técnicas da agricultura familiar, serve como exemplo de alternativa na alimentação escolar. Nesse contexto não escolar os/as alunos/as não apenas visitaram cenários diferentes, mas puderam em rodas de conversa refletir sobre a realidade encontrada e como essa realidade poderia ser levada ao ambiente escolar.

Após um planejamento com as equipes, foi organizada uma mostra dessas vivências por meio de recursos audiovisuais, poemas musicados e cartazes sensibilizadores que eram apresentados na sala de aula de cada turma da escola. Essa apresentação era encerrada com uma reflexão sobre os dados apresentados na vivência realizada pela equipe. Apesar da sobrecarga de demandas e propostas que a escola possui, os/as professores/as se utilizaram dessa iniciativa para avaliar o grau de aprendizagem de conceitos ambientais e a capacidade de envolvimento social dos/as alunos/as na temática.

Essa atividade nasceu num contexto escolar, foi extrapolada para um contexto não escolar e, numa via circular, retornou à escola com novas possibilidades, como a reativação da horta escolar e o reaproveitamento da água dos bebedouros para a limpeza da escola a partir do uso de um minigerador de energia eólica, que permitiu a armazenagem da água antes desperdiçada numa caixa d'água para posterior uso nas descargas dos vasos sanitários e lavagem do pátio da escola. Essas transformações na escola foram possíveis pela apresentação de uma realidade diferenciada que foi observada no sitio e que, a partir de uma reflexão, propiciou o envolvimento de todos os atores do contexto escolar.

No âmbito da abordagem metodológica do aprendizado sequencial um exemplo foi o engajamento de universitários nesse processo educativo de contato intenso com a natureza. As experiências diretas e profundas com a natureza são capazes de proporcionar valores e estimular atitudes em prol da conservação da natureza. Também despertam sentimentos positivos que levam os indivíduos a melhor compreender suas relações consigo, com os outros e com a natureza. Tendo esses pressupostos como base, grupos de estudantes de Turismo da Unesp participaram, de 2009 a 2010, da formação em EA na Estação Ecológica do Caiuá, localizada no município de Diamante do Norte, noroeste do estado do Paraná, divisa com o município de Rosana, em São Paulo.

Nessa proposta metodológica do aprendizado sequencial foi possível observar e perceber entre os indivíduos participantes características, gestos e ações relacionados ao afeto, à paz, à interação com o meio, ao sentimento de amor, de amizade, entre outros, que evidenciaram o envolvimento entre os elementos cognitivo (razão) e afetivo (emoção), incitando um processo de sensibilização. 
Considerou-se, portanto, que essas vivências se mostraram eficazes e possibilitaram o alcance dos objetivos da Educação Ambiental com universitários.

Outra experiência na perspectiva da educação com e na natureza é desenvolvida pela Outward Bound Brasil (OBB), em especial no programa Formação de Educadores ao Ar Livre (FEAL). Nesse curso, baseado na proposta metodológica educação experiencial, no formato de expedição, os participantes desenvolvem uma série de atividades inseridas num contexto da aventura ao ar livre.

Em 2008, o curso ocorreu na região da Serra do Cipó, MG, e contou com a participação de jovens com diferentes profissões e oriundos de diferentes estados brasileiros. Durante 21 dias esse grupo percorreu um caminho de $80 \mathrm{~km}$ passando por rios e trilhas em relevos íngremes. Além de aprenderem técnicas de canoagem, de montanhismo, de acampamento e de mínimo impacto em ambientes naturais, os participantes praticaram habilidades de logística - no carregamento dos equipamentos e alimentação - e de gestão da segurança, nas atividades interpessoais em relação ao convívio em grupo diante das vivências no ambiente desconhecido e inóspito. O objetivo era proporcionar ao participante a saída de sua zona de conforto, pois, como afirma Cascino (1998), sentir medo e angústia no contato com a natureza faz o indivíduo romper com seu comportamento habitual e esse rompimento proporciona um novo entendimento sobre o ser, sobre aquilo de que se gosta e em que se acredita. E é nesse processo de rompimento que aparece o confronto com o novo e possibilidades de mudança de atitudes e de comportamentos, aspectos fundamentais para uma nova ética em relação ao ambiente.

As experiências cotidianas em relação a todas as atividades desenvolvidas, individual ou coletivamente, bem como seus sucessos ou fracassos, eram postas em reflexão no grupo ao final do dia. Com base nessa reflexão, se definiam soluções para as situações conflituosas encontradas, desde o planejamento do percurso, da segurança e das tarefas e responsabilidades até conflitos interpessoais, que em maior ou menor escala poderiam afetar ao grupo. Essa experiência educativa foi instrutiva não apenas na capacitação do indivíduo no manejo de equipamentos e instrumentos mas na criação de condições para um novo agir em grupo, centrado em responsabilidades complementares entre os indivíduos.

Como último exemplo, mas não menos importante, mencionamos a proposta de envolvimento de professores/as do ensino médio da rede pública do estado do Amazonas no curso "A floresta amazônica e suas múltiplas dimensões", realizado com imersão total durante uma semana na estação florestal experimental do Instituto Nacional de Pesquisas da Amazônia (INPA), distante $60 \mathrm{~km}$ de Manaus, AM. Nesse curso, que ocorre desde 2003, pesquisadores/as, peões, professores/as e educadores/as vivenciam a floresta em sua plenitude, seja 
pelo caminho racional da pesquisa científica, seja pelos laços afetivos na condução e apreensão desse conhecimento. Por um lado, o/a pesquisador/a transmite a informação científica e o processo técnico nesse descobrir, o peão orienta o caminho de todos, tornando mais segura a jornada, o/a educador/a medeia e socializa as experiências e $\mathrm{o} / \mathrm{a}$ professor/a participante entra nesse mundo em sua totalidade.

As experiências multissensoriais são fundamentais nesse processo e permitem o necessário envolvimento para a reflexão e aprendizagem, levando ao entendimento de que a cognição e a emoção são dimensões indissociáveis para uma nova forma de agir e pensar (AZEVEDO; HIGUCHI, 2012). A formação integral e integradora une e relaciona conhecimentos disponibilizados pela ciência no cotidiano escolar de modo que as atividades e situações pedagógicas vivenciadas na floresta sejam reinventadas e se mostrem vivas no contexto escolar.

Os resultados dessa experiência, que já completa 10 anos, apontam uma transformação do papel do/a professor/a nas atividades escolares na relação com alunos/as e na forma de ver o trabalho do/a pesquisador/a como um/a agente não distante da realidade escolar. A relação de respeito e humildade presente nesse fazer de múltiplas mãos é um aspecto incorporado pelos/as participantes em sua continuidade no fazer escolar. A aproximação com o mundo da floresta, paradoxalmente tão distanciado da vida dos amazônidas, possibilitou a formação de novas estratégias pedagógicas e estimulou afetivamente o desenvolvimento de muitos projetos com os/as alunos/as, que mais tarde passaram a ter vivências com e na floresta. A motivação e a troca de saberes com os/as pesquisadores/as tornaram possível um diálogo mais intenso entre ciência e educação, de modo a se perceber que todos estão com o mesmo propósito: cuidar e proteger a floresta como patrimônio material e simbólico.

\section{Considerações finais}

A discussão que começa com a definição de contextos não escolares nos leva a vivências nas quais não há fronteiras de lugar, mas um compartilhar de saberes que se encontram e podem formar novos arranjos espaciais de educação. Aqui nos prendemos a fazer uma discussão destacando a natureza como um aspecto do ambiente. Sabemos que ela não é única, mas é uma dimensão que nós seres humanos estamos tratando apenas como paisagem, algo para ser admirado, porém a certa distância. Esse distanciamento precisa ser diminuído para que seja apreendido como um elo vital nas questões de sustentabilidade ambiental.

A natureza não é um lugar para onde vamos, mas um espaço que deve estar presente em nossas relações. Portanto, conhecer, sentir, tocar, admirar, se envolver, se apropriar numa relação de pertencimento sem barreiras pode ser um bom começo para o estabelecimento de uma nova ética e novos 
comportamentos de respeito e cuidado. Tais aspectos estão presentes numa proposta efetiva de Educação Ambiental transformadora.

\section{Referências}

AZEVEDO, Genoveva Chagas de; HIGUCHI, Maria Inês Gasparetto. A Floresta Amazônica como objeto de formação de docentes em educação ambiental. In: HIGUCHI, Maria Inês Gasparetto; HIGUCHI, Niro (Ed.). A Floresta Amazônica e suas Múltiplas Dimensões: uma Proposta de Educação Ambiental. 2. ed. revisada e ampliada. Manaus: Edição dos autores, 2012. p. 359-386.

BARROS, Maria Isabel Armando de. Outdoor Education: uma alternativa para a educação ambiental através do turismo de aventura. In: SERRANO, Célia (Org.). $A$ educação pelas pedras: ecoturismo e educação ambiental. São Paulo: Chronos, 2000. p. 85110.

BRASIL. Decreto-Lei no 9.795, de 27 de abril de 1999. Lex: legislação federal. Brasília: DF; Disponível em: <http://www.mec.gov.br/se/educacaoambiental/pdf/lei979599.pdf $>$. Acesso em: 23 out. 2005.

Lei $n^{\circ}$ 9.985, de 18 de julho de 2000. Lex: legislação federal. Brasília, 2000. Disponível em: <http://www.ibama.gov.br>. Acesso em: 23 out. 2005.

BUENO, Fernando Protti. As relações entre ecoturismo e educação ambiental no Pólo de Ecoturismo da Ilha de Santa Catarina. 2006. 207 f. Dissertação (Mestrado em Turismo e Hotelaria) - Universidade do Vale do Itajaí, Balneário Camboriú, 2006.

CARVALHO, Isabel Cristina de Moura. Educação Ambiental e Movimentos Sociais: elementos para uma história política do campo ambiental. Educação: Teoria e Prática, v. 9, n. 17, p. 46-56, jul./dez. 2001. p. 256.

A Educação Ambiental: a formação do sujeito ecológico. 4. Ed. São Paulo: Cortez, 2008,

CASCINO, Fábio. Do turismo convencional ao ecolazer: análise dos fundamentos éticos e estéticos do lazer associado à natureza. Debates Socioambientais, v. 3, n. 9, p. 8-10, 1998.

CATALÃO, Vera Lessa. As qualidades sensíveis da água. In: CATALÃO, Vera Lessa; RODRIGUES, Maria do Socorro (Org.). Água como matriz ecopedagógica - um projeto a muitas mãos. Brasília: Edição das autoras, 2006. p. 82-94.

CORNELL, Joseph. A alegria de brincar com a natureza: atividades na natureza para todas as idades. São Paulo: Melhoramentos, SENAC, 1997. 
DIAS, Genebaldo Freire. A educação ambiental: valores humanos e estilos de vida sustentáveis. Boletim Informativo: desenvolvimento urbano e meio ambiente, ano 2, n. 11, p. 2-3, jul./ago. 1993.

FÁVERO, Osmar. Educação Não-Formal: Contextos, Percursos e Sujeitos. Educ. Soc., Campinas, v. 28, n. 99, p. 614-617, maio/ago. 2007. Disponível em: <http://www.cedes.unicamp.br>. Acesso em: 17 jun. 2012.

FLORIANI, Dimas. Diálogos interdisciplinares para uma agenda socioambiental: breve inventário do debate sobre ciência, sociedade e natureza. Desenvolvimento e Meio Ambiente, n. 1, p. 9-16, jan./jun. 2000.

GUIMARÃES, Mauro. Educação Ambiental Crítica. In: LAYRARGUES, Philippe Pomier (Coord.). Identidades da educação ambiental brasileira. Brasília: Ministério do Meio Ambiente, 2004. p. 25-34.

GUIMARÃES, Mauro; VASCONCELLOS, Maria das Mercês N. Relações entre educação ambiental e educação em ciências na complementaridade dos espaços formais e não formais de educação. Educar em Revista, Curitiba, n. 27, p. 147-162, 2006.

HAM, Sam H. Interpretación ambiental: una guía práctica para gente con grandes ideas y presupuestos pequeños. Colorado: Fulcrum Golden, 1992.

HIGUCHI, Maria Inês Gasparetto; AZEVEDO, Genoveva Chagas de. Educação como processo de construção da cidadania ambiental. Revista Brasileira de Educação Ambiental, Brasília, v. 1, n. 0, p. 63-70, 2004.

HIGUCHI, Maria Inês Gasparetto; AZEVEDO, Genoveva Chagas de; FORSBERG, Sylvia Souza. A floresta e sociedade: ideias e práticas históricas. In: HIGUCHI, Maria Inês Gasparetto; HIGUCHI, Niro (Ed.). A Floresta Amazônica e suas Múltiplas Dimensões: uma Proposta de Educação Ambiental. 2. ed. revisada e ampliada. Manaus: Edição dos autores, 2012. p. 107-120.

INSTITUTO ROMÃ. Fundamentos. Disponível em: < http://www.institutoroma.org.br>. Acesso em: 04 set. 2008.

LAYRARGUES, Philippe Pomier. Educação para gestão ambiental: a cidadania no enfrentamento político dos conflitos socioambientais. In: LOUREIRO, Carlos Frederico Bernardo; LAYRARGUES, Philippe Pomier; CASTRO, Ronaldo Souza de (Org.). Sociedade e Meio Ambiente: a educação ambiental em debate. 6. ed. São Paulo: Cortez, 2010. p. $87-155$.

LEONARDI, Maria Lúcia Azevedo. A educação ambiental como um dos instrumentos de superação da insustentabilidade da sociedade atual. In: CAVALCANTI, Clóvis (Org.). Meio ambiente, desenvolvimento sustentável e políticas públicas. 2. ed. São Paulo: Cortez; Recife: Fund. Joaquim Nabuco, 1999. p. 391-408. 
LOUREIRO, Carlos Frederico Bernardo. Educação Ambiental Transformadora. In: LAYRARGUES, Philippe Pomier (Coord.). Identidades da educaşão ambiental brasileira. Brasília: Ministério do Meio Ambiente, 2004. p. 65-84.

MENDONÇA, Rita. A experiência na natureza segundo Joseph Cornell. In: SERRANO, Célia (Org.). A educação pelas pedras: ecoturismo e educação ambiental. São Paulo: Chronos, 2000. p. 135-154.

A proposta da Sharing Nature do Brasil. In: MINISTÉRIO DO MEIO AMBIENTE; MINISTÉRIO DA EDUCAÇÃO. O desafio do movimento Sharing Nature na educação ambiental contemporânea. Brasília: Órgão Gestor da Política Nacional de Educação Ambiental, 2006. p. 15-20. (Série Documentos Técnicos, n. 6).

MURTA, Stela Maris; GOODEY, Brian. Interpretação do patrimônio para visitantes: um quadro conceitual. In: MURTA, Stela Maris; ALBANO, Celina (Org.). Interpretar o patrimônio: um exercício do olhar. Belo Horizonte: Ed. UFMG, 2002. p. 13-46.

OUTWARD BOUND BRASIL. Metodologia. Disponível em: <http://www.obb.org.br>. Acesso em: 23 out. 2005.

PALHARES, José Augusto. Os sítios de educação e socialização juvenis: experiências e representações num contexto não-escolar. Educação, Sociedade \& Culturas, n. 27, p. 109130, 2008.

RIBEIRO, Maria de Nazaré de Lima; HIGUCHI, Maria Inês Gasparetto. A floresta como espaço de lazer e turismo. In: HIGUCHI, Maria Inês Gasparetto; HIGUCHI, Niro (Ed.). A Floresta Amazônica e suas Múltiplas Dimensões: uma Proposta de Educação Ambiental. 2. ed. revisada e ampliada. Manaus: Edição dos autores, 2012. p. 331-358.

SAUVÉ, Lucie. L'approche critique en éducation relative à l'environnement: origines théoriques et applications à la formation des enseignants. Revue des Sciences de l'Éducation, v. 23, n. 1, p. 169-187, 1997.

Uma cartografia das correntes em educação ambiental. Trad. Ernani Rosa. In: SATO, Michèle; CARVALHO, Isabel Cristina de Moura (Org.). Educação Ambiental: pesquisa e desafios. Porto Alegre: Artmed, 2005. p. 17-44.

SHARING NATURE FOUNDATION. Flow learning ${ }^{\text {TM }}$ Available from: <http://www.sharingnature.com/FlowLearning.html>. Cited: 09 Nov. 2008.

SORRENTINO, Marcos. Educação Ambiental e Universidade: um estudo de caso. 1995. 263 f. Tese (Doutorado em Educação) - Faculdade de Educação, Universidade de São Paulo, São Paulo, 1995. 
SOUZA JÚNIOR, Xisto Serafim de Santana de; ITO, Claudemira Azevedo. Turismo e espaço: uma leitura geográfica da interferência da atividade turística no processo de (re)organização sócio-espacial do município de João Pessoa-PB. Scripta Nova, Barcelona, v. 9, n. 194 (116), ago. 2005.

TUAN, Yi-fu. Topofilia: Um Estudo da Percepção, Atitudes e Valores do Meio Ambiente. São Paulo: Difel, 1980.

Artigo recebido em 12/09/2012

Artigo aprovado em 05/12/2012 